\title{
Accumulation of Glucose and Galactose by Streptococcus faecalis
}

\author{
By P. O. WILKINS* AND D. J. O'KANE \\ Laboratory of Microbiology, Division of Biology, University of \\ Pennsylvania, Philadelphia, Pennsylvania
}

(Received 5 July 1963)

\begin{abstract}
SUMMARY
Glucose and galactose are accumulated against a concentration difference by Strepiococcus faecalis strain 10c1 which has been treated with iodoacetate to eliminate glycolysis. The rate and extent of accumulation are greater for glucose than for galactose but both processes show saturation kinetics, stereospecificity, and sensitivity to metabolic inhibitors. Accumulated sugar does not exchange with glucose or galactose in the external medium. Loss of internal sugar is a relatively slow first-order reaction. Both accumulation and loss are temperature dependent. Preincubation of the organisms in arginine increases the rate and extent of accumulation and decreases the rate of loss. A model is proposed in which hexose accumulation results from an energy-dependent adsorption to specific, thermolabile receptors.
\end{abstract}

\section{INTRODUCTION}

Experiments designed for the study of carbohydrate transport in bacteria have frequently made use of two alternative conditions in order to dissociate the entry of the sugar from its subsequent phosphorylation and metabolic breakdown: (1) an analogue of the sugar is chosen which is able to penetrate the cell but which is not a substrate for the available glycolytic enzymes (Cohen \& Monod, 1957); or (2) a mutant is selected which can accumulate the natural sugar but which is unable to metabolize it (Horecker, Thomas \& Monod, 1960). During investigations in this laboratory on the metabolism of carbohydrates by Streptococcus faecalis strain $10 \mathrm{cl}$, it was noted that free glucose and galactose were accumulated by cocci in which glycolysis had been eliminated by treatment with iodoacetate (Wilkins \& O'Kane, 1961). This observation suggested the possibility of studying hexose transport independently of both substrate analogues and mutants. The work presented here is concerned with characterizing the accumulation of glucose (a metabolizable sugar) and galactose (which is not metabolized by glucose-grown cocci) in terms of entry and exit rates, stereospecificity, energy requirements, and sensitivity to metabolic inhibitors.

\section{METHODS}

Preparation of suspensions of cocci. The organism, Streptococcus faecalis strain $10 \mathrm{cl}$, was grown at $37^{\circ}$ in a medium containing $0 \cdot 1 \%$ glucose, $0 \cdot 3 \% \mathrm{~K}_{2} \mathrm{HPO}_{4}, 1 \cdot 0 \%$

* Present address: Departments of Microbiology and Biochemistry, Seton Hall, College of Medicine and Dentistry, Jersey City, New Jersey, U.S.A. 
yeast extract, and $1.0 \%$ tryptone. The cocci were harvested in the late logarithmic growth phase, washed in and resuspended in 2-amino-2-hydroxymethylpropane-1,3diol (tris) + maleate buffer $(\mathrm{pH} 7.0 ; 0.03 \mathrm{M})$ so that a $1 \mathrm{ml}$. volume of reaction system would contain the equivalent of $1 \cdot 6 \pm 0 \cdot 2 \mathrm{mg}$. dry-weight cocci. This quantity represents a compromise between an amount of cocci small enough to permit rapid collection on a membrane filter and large enough to accumulate measurable amounts of radioactivity from low concentrations of ${ }^{{ }^{14}} \mathrm{C}$-labelled substrate. The equivalent dry weight of cocci was determined turbidimetrically in an Evelyn Photoelectric Colorimeter by using a suitable calibration curve.

Apparatus. In most experiments the cocci were removed from a reaction mixture containing $10^{-3} \mathrm{M}$-iodoacetate and a radio-active hexose by means of a closedsystem membrane filter that could be immersed in a water bath for the control of temperature (Fig. 1). Cocci, substrate and other reagents could be placed in the reaction tube compartments (shown inverted in Fig. 1) before the two sections of the filter unit were clamped together. Subsequent additions were made by syringe through Port 1 (Fig. 1, (3)). At the end of the reaction time, the mixture was tipped on to a Millipore HA filter $(\mathbf{2 5} \mathrm{mm}$. diam.) by rotating the entire unit. Suction was applied at the filtrate tube (Port 2, Fig. 1, (7)) and the soluble reaction constituents passed through the filter within $20 \mathrm{sec}$. One $\mathrm{ml}$. of tris + maleate buffer was injected through Port 1 immediately after tipping to wash down the drop of reaction mixture that hangs from the reaction tube. The cocci were washed with two additional $1 \mathrm{ml}$. portions of buffer and the membrane, with adhering cocci, was promptly removed. Since individual determinations entailed several manipulations extending over a considerable period of time, the apparatus was arranged so that four independent filter units could be used simultaneously.

When, as in exit rate experiments, preloaded cocci were to be resuspended above the filter membrane, the suction at Port 2 was turned off, a slight suction was applied at Port 3 (Fig. 1, (2)) and the appropriate solution was added through Port 1. The resuspending solution did not leak through the filter under these conditions but could be quickly removed by reversing the direction of suction.

The substrate solutions were prepared from weighed quantities of glucose- ${ }^{14} \mathrm{C}$ (uniformly labelled) from Nuclear-Chicago Corp. and galactose-1-14 $\mathrm{C}$ obtained from the National Bureau of Standards. The radioactivity was measured with a Nuclear Instrument Corporation Geiger counter (model 153). The glucose ${ }^{14} \mathrm{C}$ had 18,000 c.p.m. per $\mu$ mole and the galactose-1-14C had 48,000 c.p.m. per $\mu$ mole. Sufficient counts were recorded to yield a probable error of less than $2 \%$.

The radioactivity remaining with the cocci after they had dried on the filter membrane was usually interpreted as the $\mu$ moles sugar accumulated/g. dry wt. of cocci. The internal substrate concentration was estimated by dividing the amount of sugar accumulated by the volume of intracellular water. The intercellular water content of the packed cell mass determined by the inulin method of Conway \& Downey (1950) was very close to the theoretical value of $26 \%$ for close-packed spheres. The water content of the cocci was assumed to be $80 \%$ (Luria, 1960), and the percentage of the packed cell mass representing intracellular water presumably available to dissolve hexose was therefore taken to be $\mathbf{0 . 7 4}$ (correction for intercellular water $) \times 0 \cdot 80$ (intracellular water) $\times$ the packed cell volume.

Chemical analyses. Reducing sugars were determined by Nelson's (1944) modi- 
fication of the Somogyi method. Lactic acid was measured by the method of Barker (1957). Ammonia production from arginine was measured with Nessler's reagent prepared by the method of Vanselow (1946). Chromatography of free sugars was carried out by the method of Jermyn \& Isherwood (1949) using ethyl acetate + py ridine + water $(2+1+2$, by vol. $)$ as the developing solvent and aniline oxalate as the spray.

Kinetics of sugar transport. Hexose accumulation in Streptococcus faecalis can be considered in terms of the equations presented by Cohen \& Monod (1957) for permease mediated sugar transport in Escherichia coli. In this model, net accumulation is a balance between an entry reaction which follows saturation kinetics and an independent first-order exit reaction. The change in the internal substrate concentration, $S_{i}$, may be represented by

$$
\frac{d S_{i}}{d t}=y\left(\frac{S_{e}}{S_{e}+K}\right)-c\left(S_{i}\right)
$$

where $S_{e}$ is the external concentration, $K$ is the external concentration at which halfmaximum accumulation occurs, $y$ is the maximum transport capacity of the system, and $c$ is the exit rate constant.

At equilibrium, $S_{i}$ is constant. Substituting $d S_{i} / d t=0$, and $y / c=Y$ in equation (1) and taking reciprocals gives

$$
\frac{1}{S_{i}}=\frac{1}{Y}+\frac{K}{Y}\left(\frac{1}{S_{e}}\right)
$$

from which the constants may be determined by the conventional LineweaverBurk plot of $1 / S_{i}$ vs $1 / S_{e}$.

\section{RESUL'TS}

\section{Inhibition of glycolysis by iodoacetate}

Preliminary experiments with concentrated coccal suspensions ( 1 g. wet wt./ml.) showed that iodoacetate-poisoned suspensions (exposed to either glucose or galactose) accumulated reducing activity that could be extracted from the cocci by $5 \mathrm{~min}$. exposure to $100^{\circ}$ after treatment of a $1 \mathrm{ml}$. sample with $1 \mathrm{ml}$. acetone, allowing to stand a few min., and adding $1 \mathrm{ml}$. of water. Chromatography of samples of the extracts showed either free glucose or free galactose in approximately the amount expected (indicating that phosphorylation and subsequent metabolic steps had been eliminated by treatment with iodoacetate). To facilitate experimentation, the coccal concentration was decreased, and the sugar uptake followed by radioactivity alone.

Glucose metabolism was not stopped immediately upon the addition of $10^{-3} \mathrm{M}$ iodoacetate. Manometric experiments showed that oxygen consumption and acid production did occur in reaction systems similar to those used in the accumulation studies described below unless the iodoacetate was added $15 \mathrm{~min}$. before the addition of glucose. The cocci were therefore routinely incubated with iodoacetate for $20 \mathrm{~min}$. before the sugar was added. Under these conditions, chemical analyses showed no loss of glucose from the medium and no production of lactic acid. The procedure used for the determination of glucose was not sensitive enough to detect the amount removed from the medium by the accumulation process but it could be 
expected to reveal, over an extended reaction time, a very slow metabolic utilization of glucose. Although galactose was not fermented by glucose-grown cocci, iodoacetate was included in the experiments with galactose.

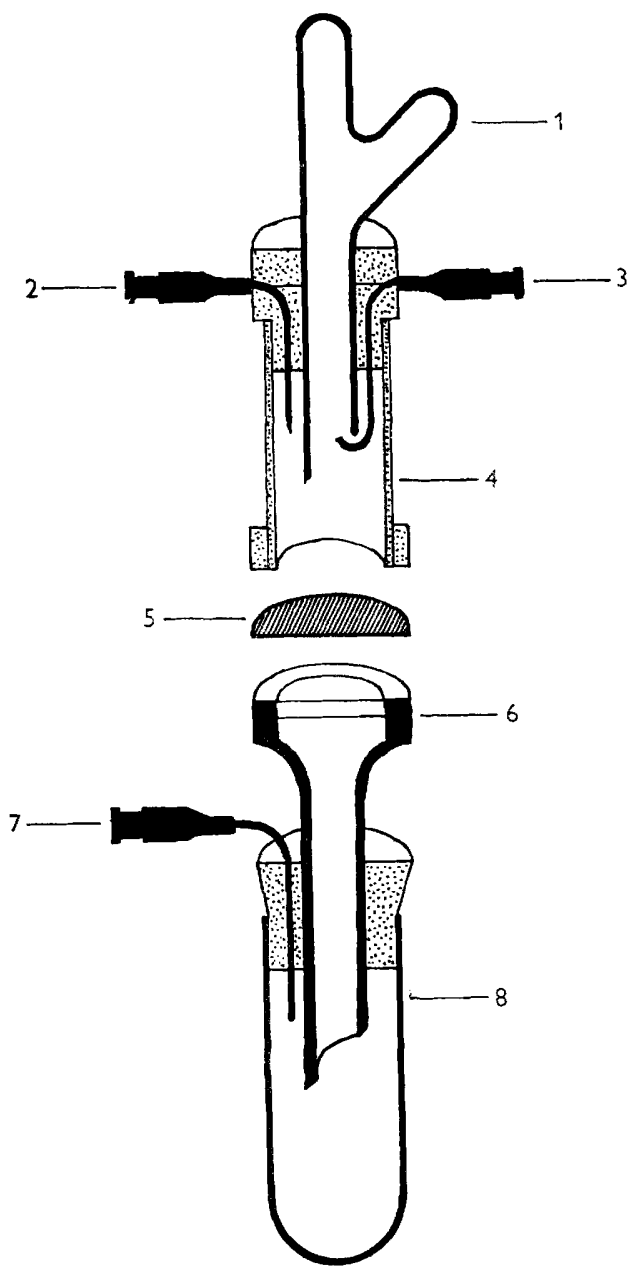

Fig. 1

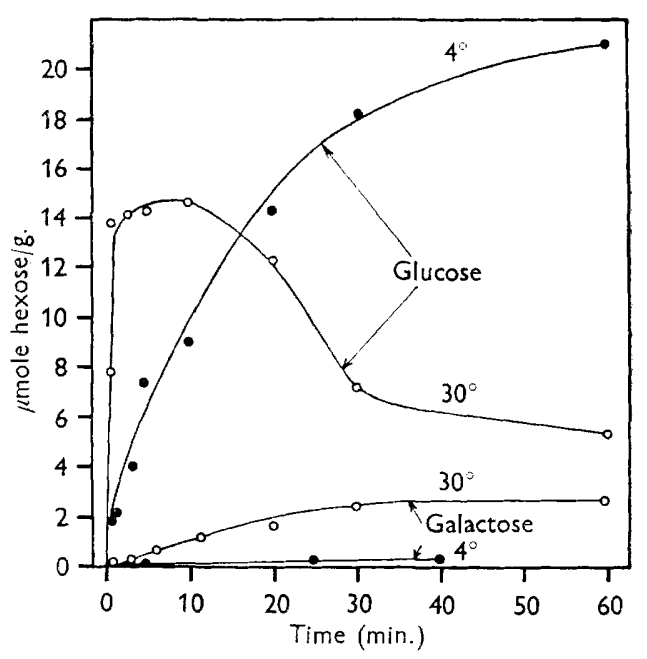

Fig. 2

Fig. 1. Closed system membrane filter. (1) Glass reaction tube; (2) Port 3 (no. 20 hypodermic needle) suction line coupling; (3) Port 1, inlet for solutions; (4) Acrylite cylinder; (5) Millipore HA filter membrane $(25 \mathrm{~mm}$. diam.) (6) Millipore filter base; (7) Port 2, suction line coupling; (8) filtrate tube. The cylinder is clamped to the base after the compartments of the reaction tube (shown inverted) have been filled. For operational procedures, see text.

Fig. 2. Time course of glucose and galactose accumulation. Each reaction tube contained (1.0 ml.): cocci, equiv. $1.6 \mathrm{mg}$. dry weight; tris + maleate buffer (pH 7.0), $13 \mu$ mole; hexose-14 $\mathrm{C}, 0.1 \mu$ mole; iodoacetate, $1.0 \mu$ mole added $20 \mathrm{~min}$. before the addition of the sugar. At the end of the indicated accumulation times, the cocci were collected, washed (in three $1 \mathrm{ml}$. portions of buffer) and allowed to dry on the filter membrane. The specific activities of the hexoses were: glucose 18,000 c.p.m./ $\mu \mathrm{M}$, galactose 48,000 c.p.m./ $\mu \mathrm{M}$. 


\section{Accumulation of glucose and galactose}

The time course of glucose and galactose accumulation, at $4^{\circ}$ and $30^{\circ}$, from external concentrations of $10^{-4} \mathrm{M}$ is shown in Fig. 2. The initial rate of glucose uptake was too rapid for accurate measurement, even at low temperatures, and thus the $Q_{10}$ for glucose entry could not be determined. The time and extent of maximum glucose accumulation tended to vary with the coccal preparation despite efforts to keep growth conditions and preparatory manipulations constant. At $30^{\circ}$ the cocci accumulated $90 \%$ of the maximum amount in less than 1 min.; a gradual loss of most, but not all, of the internal glucose followed. At $37^{\circ}$ maximum glucose values were considerably lower than those at $30^{\circ}$ possibly because, as Winters, Delluva, Deyrup \& Davies (1962) postulated for sulphate accumulation in kidney mitochondria, uptake and subsequent loss at $37^{\circ}$ may occur within a very short time interval. The internal glucose value at $20^{\circ}$ was higher than at $30^{\circ}$, and it remained relatively stable. At temperatures below $20^{\circ}$, accumulation values were still higher and no loss of previously accumulated glucose was observed.

Table 1. Hexose accumulation by Streptococcus faecalis against a concentration difference

The experimental conditions were those given in the legend to
concentration, $S_{i}$, was estimated as described in Methods. Th
tion, $S_{e}$, at the steady state equals the amount of sugar originally
accumulated.
$\begin{array}{ccc}S_{e} \text { at start } & S_{i} / S_{e} \text { at the steady state } \\ \left(\text { Molar } \times 10^{5}\right) & \text { Glucose } & \text { Galactose } \\ 100 & 4 \cdot 2 & 3 \cdot 0 \\ 70 & 6 \cdot 2 & 4 \cdot 3 \\ 50 & 8 \cdot 6 & 6 \cdot 4 \\ 30 & 13 & 9 \cdot 1 \\ 10 & 38 & 14 \\ 5 & 69 & 14 \\ 1 & 90 & -\end{array}$

'The initial rates of galactose uptake were readily measured (Fig. 2) and were reproducible within narrow limits. Unlike glucose uptake, the accumulation of galactose was negligible at $4^{\circ}$. Between $20^{\circ}$ and $37^{\circ}$ the $Q_{10}$ value was $2 \cdot 2$. Net loss of internal galactose did not occur for at least $3 \mathrm{hr}$, but, when the starting external concentrations were the same, the maximum value for galactose was less than the final value for glucose.

Figure 3 shows the effect of external concentration on maximum accumulation values of glucose and galactose at $30^{\circ}$. The apparent Michaelis constants, calculated from the data in Fig. 3 by the method indicated in equation (2), are $3 \cdot 1 \times 10^{-5} \mathrm{M}$ for glucose, and $3 \cdot 4 \times 10^{-4} \mathrm{M}$ for galactose. The extent of accumulation against concentration differences may be determined by converting the accumulation values in Fig. 3 to internal molar concentrations (Table 1). Both sugars were unquestionably transported 'uphill' and the ratio of internal to external substrate concentration $\left(S_{i} / S_{e}\right)$ increased with a decrease in $S_{e}$. Higher ratios were obtained for glucose than for galactose, but $S_{i} / S_{e}$ did not reach the extremely high values found for sugar transport in Escherichia coli (Cohen \& Monod, 1957; Horecker et al. 1960). 
Since uphill accumulation depends in part on the amount of energy available, the presence of an energy-yielding substrate in the reaction system would be expected to increase $\boldsymbol{S}_{i} \mid \boldsymbol{S}_{e}$. Arginine fermentation by Streptococcus faecalis, which has been shown to produce A'TP (Oginsky, 1955), was found not to be inhibited by iodoacetate. Pre-incubation of the cocci in $10^{-2} \mathrm{M}$-arginine for one hour before addition of glucose or galactose increased the accumulation of both sugars (Table 2) and eliminated the loss of internal glucose which normally follows uptake at temperatures above $20^{\circ}$ (Table 3). However, under these conditions, $S_{i} / S_{e}$ did not increase with a decrease in $S_{e}$ (Table 2) even though accumulation times were extended from 10 to $60 \mathrm{~min}$. for glucose, and from 30 to $120 \mathrm{~min}$. for galactose.

\section{Table 2. Effect of arginine on accumulation of hexose by \\ Streptococcus faecalis against a concentration difference}

Arginine $\left(10^{-2} \mathrm{M}\right)$ was added $60 \mathrm{~min}$. before the addition of the sugar. The other reaction components were the same as those given in the legend to Fig. 2. Accumulation times: glucose, $30 \mathrm{~min}$; galactose, $120 \mathrm{~min}$. Temperature, $30^{\circ} . S_{i}=$ internal concentration; $S_{e}=$ external concentration

$\begin{array}{ccc}\begin{array}{c}S_{e} \text { at start } \\ \left(\text { Molar } \times 10^{5}\right)\end{array} & \overbrace{\text { Glucose }} S_{\text {Galactose }} \text { at the steady state } \\ 20 & 165 & 18 \\ 10 & 180 & 19 \\ 5 & 120 & 21 \\ 2 & 190 & 17\end{array}$

Table 3. Effect of arginine on glucose accumulation by Streptococcus faecalis

The reaction components were the same as listed in the legend to Fig. 2 plus $10 \mu$ moles arginine added $60 \mathrm{~min}$. before the addition of glucose- ${ }^{14} \mathrm{C}$. Accumulation time, $45 \mathrm{~min}$.

$\begin{array}{ccc}\text { Temperature } & \begin{array}{l}\text { Without } \\ \text { arginine }\end{array} & \begin{array}{c}\text { With } \\ \text { arginine }\end{array} \\ \mathbf{2 0}^{\circ} & 10 & \mathbf{2 5} \\ \mathbf{3 5}^{\circ} & 4 & \mathbf{2 8}\end{array}$

The exit process

In the experiment illustrated by Fig. 4 glucose was accumulated without preincubation with arginine, and the cocci were washed and resuspended above the filter membrane in tris + maleate buffer. The initial exit rates, shown by the tangents in Fig. 4, were proportional to the initial internal concentrations. The kinetics of glucose exit do not correspond to a simple process, but if slopes for a first-order reaction constant of $0.1 \mathrm{~min} .^{-1}$ are drawn they are approximately tangent to the initial exit rates (Fig. 4). It seems probable from inspection of Fig. 4 that part of the internal glucose is retained by the cocci indefinitely. When appropriate values for the retained glucose are subtracted, curves 1 and 2 quite closely follow firstorder exponentials from which an average rate constant of $0 \cdot 2 \mathrm{~min}^{-1}$ can be calculated. However, a consistent relationship between the amount of internal sugar 
that is retained by the cocci and that which diffuses out was not found. The backward projection technique (Van Liew, 1962) applied to semilog plots of curves 1 and 2 did not indicate that more than one exponential process was involved.

Since most permeation systems are readily reversible, it was expected that the rate of exit of glucose-14 $\mathrm{C}$ would increase when the cocci were resuspended in a solution containing non-radioactive glucose rather than in buffer alone. No significant change in exit rate was found, however, when the cocci were resuspended in concentrations of glucose-12 $\mathrm{C}$ as high as $0 \cdot 1 \mathrm{M}$.

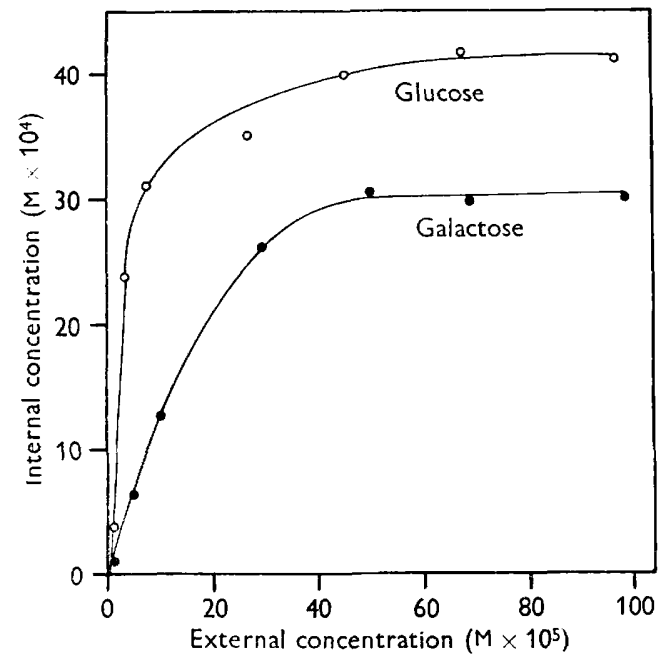

Fig. 3

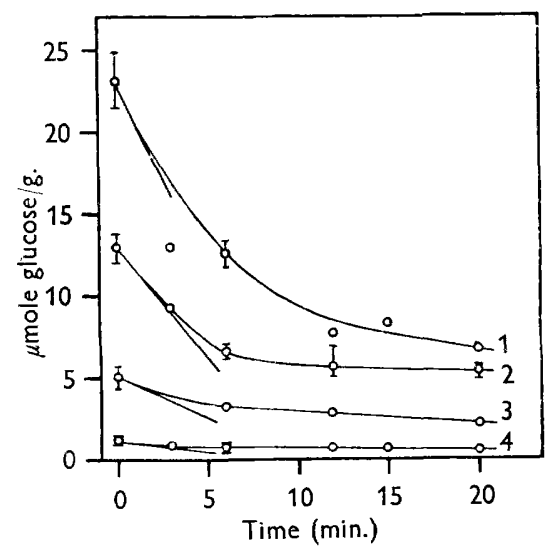

Fig. 4

Fig. 3. Effect of external concentration on the steady-state values of accumulated glucose and galactose. The reaction tubes contained cocci and iodoacetate as described in the legend to Fig. 2. Temperature, $30^{\circ}$. Ordinates: internal sugar estimated by the procedure given in Methods. Abscissa: steady-state external sugar concentrations; the amount of sugar accumulated was subtracted from the amount originally added to the medium. Accumulation times : glucose, $10 \mathrm{~min}$.; galactose, $30 \mathrm{~min}$.

Fig. 4. The effect of internal concentration on the time course of glucose exit. The cocci were incubated for $5 \mathrm{~min}$., in the absence of arginine, in reaction systems similar to that described in the legend to Fig. 2 but containing the following amounts of glucose${ }^{14} \mathrm{C}$ : curve $1,0.5 \mu$ mole; curve $2,0.1 \mu$ mole; curve $3,0.05 \mu$ mole; curve $4,0.01 \mu$ mole. The cocei were washed and resuspended above the filter membrane in tris + maleate buffer $(\mathrm{pH} 7 \cdot 0,0 \cdot 03 \mathrm{M})$ for the time intervals indicated. Temperature, $30^{\circ}$.

\section{Table 4. Exit of glucose and galactose from Streptococcus faecalis pre-incubated with arginine}

The cocci were loaded with sugar after $60 \mathrm{~min}$. pre-incubation in $10^{-2} \mathrm{M}$-arginine. First-order exit rate constants were calculated from the initial slopes of exit time course curves. Temperature $30^{\circ}$.

$\begin{array}{ccc}\text { Internal sugar } & \begin{array}{c}\text { Sugar }\left(10^{-2} \mathrm{M}\right) \text { in } \\ \text { resuspending medium }\end{array} & \begin{array}{c}\text { Exit rate } \\ \text { constant }\end{array} \\ \text { Glucose- }{ }^{14} \mathrm{C} & \text { None } & 0 \cdot 04 \\ & \text { Glucose-12 } \mathrm{C} & 0 \cdot 03 \\ \text { Galactose- }{ }^{14} \mathrm{C} & \text { None } & 0 \cdot 02 \\ & \text { Glucose-12 } \mathrm{C} & 0 \cdot 02\end{array}$


Table 4 shows that pre-incubation of the cocci in arginine before they were loaded with sugar decreased the glucose exit rate about fourfold. This effect was less marked for galactose since galactose exit from cocci that had not been incubated with arginine was slower than glucose exit. The failure of internal hexose to exchange with external sugar is also shown in Table 4.

The exit rate constant, $c$, of the permease model (Horecker et al. 1960) is calculated from accumulation time course data expressed as

$$
2 \cdot 303 \log \frac{S_{\infty}-S_{i}}{S_{\infty}}=c(t),
$$

where $S_{\infty}$ is the equilibrium value of the internal concentration, $S_{i}$, and $t$ is the accumulation time. Appropriate values of $\boldsymbol{S}_{\boldsymbol{i}}$ could not be measured for glucose accumulation by Streptococcus faecalis but, for galactose, the data in Fig. 2 yield $c=0.04$ min. $^{-1}$, which is within the same order of magnitude as values obtained from a direct measurement of exit rate.

\section{Stereospecificity}

Table 5 shows that the uptake of glucose and galactose was inhibited by the presence of other hexoses. Lactose, sucrose and inulin (used as a control) did not appreciably decrease hexose accumulation. Abrams (1960) showed that oligosaccharides are able to penetrate protoplasts of Streptococcus faecalis but our results indicate that they do not compete for the hexose accumulation mechanism.

\section{Table 5. Inhibition of accumulation by stereoisomers}

\begin{tabular}{|c|c|c|c|}
\hline $\begin{array}{l}\text { Substrate } \\
\left(10^{-4} \mathrm{M}\right)\end{array}$ & $\begin{array}{l}\text { Competing sugar } \\
\qquad\left(10^{-3} \mathrm{M}\right)\end{array}$ & $\begin{array}{c}\mu \text { mole substrate } \\
\text { accumulated } / \mathrm{g} . \\
\text { equiv. dry wt. } \\
\text { of cocci }\end{array}$ & $\begin{array}{c}\text { Inhibition } \\
(\%)\end{array}$ \\
\hline Glucose & $\begin{array}{l}\text { None } \\
\text { Galactose } \\
\text { Fructose } \\
\text { Mannose }\end{array}$ & $\begin{array}{r}14 \cdot 1 \\
13 \cdot 0 \\
5 \cdot 0 \\
6 \cdot 3\end{array}$ & $\begin{array}{r}0 \\
7 \\
64 \\
55\end{array}$ \\
\hline Galactose & $\begin{array}{l}\text { None } \\
\text { Glucose } \\
\text { Fructose } \\
\text { Mannose }\end{array}$ & $\begin{array}{l}2 \cdot 5 \\
0 \cdot 2 \\
1 \cdot 6 \\
0 \cdot 4\end{array}$ & $\begin{array}{r}0 \\
92 \\
36 \\
34\end{array}$ \\
\hline
\end{tabular}

\section{Sensitivity to metabolic inhibitors}

Inhibition of accumulation by $p$-chloromercuribenzoate (PCMB) and uranylacetate is shown in Table 6. PCMB did not inhibit uptake unless it was added to the cocci some minutes before the addition of the sugar. Uranylacetate was immediately effective, which suggests that it acts in Streptococcus faecalis, as it does in yeast (Rothstein, 1954), by blocking uptake at the cell surface. Inhibition of sugar transport by PCMB has been observed with several cell types (Le Fevre, 1954; Randle, 1960; Kepes, 1960) and is considered to be evidence for the participation in 
transport of an enzyme-like protein. The accumulation mechanism is also sensitive to iodoacetate, since an increase in concentration beyond the limit that ensured the blocking of glycolysis resulted in lower values for internal sugar.

\section{Table 6. Inhibition of accumulation by uranylacetate and p-chloromercuribenzoate $(P C M B)$}

\begin{tabular}{|c|c|c|c|}
\hline $\begin{array}{c}\text { Substrate } \\
\left(10^{-4} M\right)\end{array}$ & Inhibitor & $\begin{array}{l}\mu \text { mole substrate } \\
\text { accumulated } / g . \\
\text { of equiv. } \\
\text { dry wt. } \\
\text { cocci }\end{array}$ & $\begin{array}{c}\text { Inhibition } \\
(\%)\end{array}$ \\
\hline Glucose & $\begin{array}{l}\text { None } \\
\text { Uranylacetate } \\
\text { PCMB }\end{array}$ & $\begin{array}{r}18 \cdot 0 \\
0 \cdot 8 \\
3 \cdot 1\end{array}$ & $\begin{array}{r}0 \\
96 \\
83\end{array}$ \\
\hline Galactose & $\begin{array}{l}\text { None } \\
\text { Uranylacetate } \\
\text { PCMB }\end{array}$ & $\begin{array}{l}2 \cdot 5 \\
0 \cdot 1 \\
0 \cdot 1\end{array}$ & $\begin{array}{r}0 \\
96 \\
96\end{array}$ \\
\hline
\end{tabular}

\section{DISCUSSION}

The accumulation of glucose and galactose by Streptococcus faecalis (in the absence of glycolysis) has two principal characteristics: (1) an energy-dependent mechanism that permits uptake against a concentration difference and which shows saturation kinetics, stereospecificity and sensitivity to metabolic inhibitors; (2) a relatively slow exit that can be inhibited by incubating the cocci with arginine but which is independent of the external substrate concentration. These features agree in several respects with the permease theory for sugar transport (Cohen \& Monod, 1957; Horecker et al. 1960) but the lack of exchange between internal and external substrate is an important difference. Since the permease theory depends to a considerable extent on experiments involving substrate displacement reactions (Cohen \& Monod, 1957; Horecker et al. 1960; Kepes, 1960), its applicability to sugar accumulation in $S$. faecalis seems questionable.

An alternative hypothesis was suggested by Dr V. P. Cirillo (personal communication) in which accumulation results from intracellular adsorption to specific receptors. According to this view, free internal sugar is in equilibrium with the external sugar at all times, irrespective of the mechanism of transport; but accumulation against a concentration difference depends on two irreversible processes as shown in the following scheme:

$$
S+\underbrace{A \stackrel{k_{1}}{\longrightarrow} \overline{A S} \stackrel{k_{2}}{\longrightarrow} S+I}_{\text {energy }} .
$$

The substrate, $S$, combines with an activated receptor, $A$, to form a thermolabile complex, $\overline{A S}$, which can dissociate to form free $S$ and an inactivated receptor, $I$. The regeneration of $A$ from $I$ requires metabolic energy. In the absence of a sufficient number of activated sites, desorbed $S$ will diffuse out of the cell. Since 
the cell membrane is freely permeable to hexoses, the substrate retained by washed cocci is entirely in the bound form. Thus the change in the internal concentration can be expressed as

$$
\frac{\overline{d \bar{A}}}{d t}=k_{1}(S)(A)-k_{2}(\overline{A S}) .
$$

The total number of receptors, $A_{t}$, may be defined as $A_{t}=A+\overline{A S}+I$. Therefore

$$
\frac{d \overline{A S}}{d t}=k_{1}(S)\left(A_{t}-\overline{A S}-I\right)-k_{2}(\overline{A S}) .
$$

In the steady state, $d \overline{A S} / d t=0$. Thus

If we define $k_{2} / k_{1}=K$,

$$
S\left(A_{t}-I\right)-\overline{A S}\left(S+\frac{k_{2}}{k_{1}}\right)=0 .
$$

$$
\overline{A S}=\left(A_{t}-I\right) \frac{S}{S+K} .
$$

Taking reciprocals yields an expression that is formally equivalent to equation (2),

$$
\frac{1}{\overline{A S}}=\frac{1}{\left(A_{t}-I\right)}+\frac{K}{\left(A_{t}-I\right)}\left(\frac{1}{S}\right) \text {. }
$$

When energy resources are sufficiently high, the concentration of $I$ will be negligible and $\left(A_{t}-I\right)$ will be a constant equal to the maximum number of receptor sites. The constant, $K$, which represents the ratio of the rate of breakdown to the rate of formation of the complex, can then be evaluated from a Lineweaver-Burk plot of equation (8).

This scheme offers an explanation for most of the data on hexose accumulation by Streptococcus faecalis. It predicts that the energy supplied by arginine metabolism would have the observed effect of increasing the accumulation rate and decreasing the exit rate. It would also account for the prevention of the loss of internal glucose after an initial accumulation period at temperatures above $20^{\circ}$. In this respect the adsorption scheme is similar to the model proposed by Winters et al. (1962) for kidney mitochondria in which uptake and subsequent loss of sulphate is a function of thermolabile binding sites that can be partially stabilized by oxidative phosphorylation. The adsorption model, like the permease model, does not explain why the ratio of internal to external sugar remains constant over a tenfold range in external concentration after pre-incubation with arginine. It also does not account for the observation that part of the accumulated sugar is retained by the cocci indefinitely. One might postulate, however, that two types of adsorption complexes are formed, one of which does not dissociate under the conditions studied.

The authors would like to thank Dr V.P. Cirillo for reading and discussing the manuscript. One of us (P. O. W.) was a trainee on Training Grant 2G-517 from the Division of General Medical Sciences, U.S. Public Health Service. 


\section{REFERENCES}

Abrams, A. (1960). Metabolically dependent penetration of oligosaccharides into bacterial cells and protoplasts. J. biol. Chem. 235, 1281.

Barker, S. B. (1957). Preparation and colorimetric determination of lactic acid. Methods in Enzymology. Ed. by S. P. Colowich \& N. O. Kaplan, vol. 3, p. 241. New York: Academic Press Inc.

Conen, G. N. \& Monod, J. (1957). Bacterial permeases. Bact. Rev. 21, 169.

Conway, E. J. \& Downey, M. (1950). An outer metabolic region of the yeast cell. Biochem. J. 47, 347.

Horecker, B. L., Thomas, J. \& Monod, J. (1960). Galactose transport in Escherichia coli. J. biol. Chem. 235, 1580.

JERMYN, M. A. \& IsHerwood, F. A. (1949). Improved separation of sugars on the paper partition chromatogram. Biochem. J. 44, 402.

KEPES, A. (1960). Etudes cinétiques sur la galactose-perméase d'Escherichia coli. Biochim. biophys. Acta, 40, 70.

LE FEvre, P. G. (1954). The evidence for active transport of monosaccharides across the red cell membrane. In Active Transport and Secretion. Symp. Soc. exp. Biol. 8, 118.

LURIA, S. E. (1960). The bacterial protoplasm: composition and organization. In The Bacteria. Ed. by I. C. Gunsalus \& R. Y. Stanier. Vol. 1, p. 1. New York: Academic Press.

Nelson, N. (1944). A photometric adaptation of the Somogyi method for the determination of glucose. J. biol. Chem. 153, 375 .

OGINSKY, E. L. (1955). Mechanisms of arginine and citrulline breakdown in microorganisms. In Amino Acid Metabolism. Ed. by W. D. McElroy \& H. B. Glass, p. 300. Baltimore: Johns Hopkins Press.

RaNdLe, P. J. (1960). Monosaccharide transport in muscle and its regulation. In Membrane Transport and Metabolism. Ed. by A. Kleinzeller \& A. Kotyk, p. 431. New York: Academic Press Inc.

Rothstein, A. (1954). Enzyme systems of the cell surface involved in the uptake of sugars by yeast. In Active Transport and Secretion. Symp. Soc. exp. Biol. 8, 165.

van Liew, H. D. (1962). Semilogarithmic plots of data which reflect a continuum of exponential processes. Science, 138, 682.

Vanselow, A. P. (1946). Preparation of Nessler's reagent. Industr. Engng Chem. (Anal.), $12,515$.

Wilkins, P. O. \& O'Kane, D. J. (1961). The accumulation of glucose and galactose by Streptococcus faecalis. Bact. Proc. p. 189.

Winters, R. W., Delluva, A. M., Deyrup, I. J. \& Davies, R. E. (1962). Accumulation of sulfate by mitochondria of rat kidney cortex. J. gen. Physiol. 45, 757. 